\title{
MEDIA MEDAN PERKALIAN DAN PEMBAGIAN BILANGAN BULAT
}

\author{
Salim \\ 1)Jurusan Pendidikan Matematika, Universitas Halu Oleo, Jl. H.E.A. Mokodompit Kampus Hijau \\ Bumi Tridharma Anduonohu Kota Kendari; salim@uho.ac.id
}

\begin{abstract}
Abstrak. Matematika merupakan mata pelajaran yang dianggap sulit oleh sebagian siswa sehingga menyebabkan menurunnya minat dan motivasi belajar dalam diri siswa dalam mempelajari dan memahami konsep matematika. Dalam proses pembelajaran di kelas, matematika yang terkesan rumit dan menjadi kesan buruk bagi sebagian siswa merupakan kendala untuk siswa dalam menyelesaikan permasalahan-permasalahan sehari-hari yang berhubungan dengan matematika. Untuk mengatasi itu diperlukan sebuah inovasi media dalam pembelajaran matematika sebagai jembatan bagi siswa untuk memahami konsep abstrak dari obyek matematika melalui manipulasi bendabenda nyata. Artikel ini bertujuan untuk menyajikan cara pembuatan dan penggunaan media medan perkalian dan pembagian bilangan bulat untuk siswa SD. Media medan perkalian dan pembagian bilangan bulat ini sangat cocok sebagai media pembelajaran yang dapat digunakan untuk mengajarkan pemahaman konsep perkalian dan pembagian kepada peserta didik khususnya SD kelas II. Dengan media ini, siswa tidak hanya dapat berhitung tentang perkalian dan pembagian bilangan bulat, namun dapat memahami dengan mudah konsep perkalian dan pembagian bilangan bulat.
\end{abstract}

Kata Kunci. Bilangan Bulat, Medan Perkalian dan Pembagian, Media.

\section{The Media of Medan Perkalian dan Pembagian Bilangan Bulat}

\begin{abstract}
Mathematics is considered as a difficult subject for some students, leading to a decrease in students' interest and motivation in understanding mathematical concept. In the process of classroom teaching and learning, mathematics that seems complicated and makes a bad impression for some students is an obstacle for them in solving daily mathematical problems. To deal with this obstacle, a media innovation in mathematics teaching and learning is deemed necessary as a bridge for students to understand the abstract concepts of mathematical objects through the manipulation of real objects. This paper aims to present how to create and use the media of Medan Perkalian dan Pembagian Bilangan Bulat for elementary school students. This media are quite appropriate as a learning medium used to help students understand the concept of multiplication and division, especially for grade II of elementary school students. Using this medium, students are not only capable to deal with multiplication and the division of integers but also easily understand the concept of multiplication and integers division.
\end{abstract}

Keyword. Integer, Multiplication and Division Field, Media

\section{Pendahuluan}

Matematika merupakan ilmu pasti dan bersifat abstrak, namun memberikan banyak manfaat dalam aktivitas kehidupan manusia. Herlina (2016) mengungkapkan bahwa matematika menjadi alat komunikasi dan alat berpikir untuk menganalisis suatu ilmu dan teknologi. Pada aspek pembelajaran, matematika menuntut siswa untuk dapat menguasai dan mengikuti 
aturan yang berlaku dalam matematika sehingga memiliki keberartian untuk menyumbangkan pengaruh positif dalam kehidupan sehari-hari. Matematika adalah satu dari beberapa mata pelajaran yang dianggap sulit oleh sebagian siswa. Anggapan tersebut yang menyebabkan menurunnya minat dan motivasi belajar dalam diri siswa dalam mempelajari dan memahami konsep matematika. Dalam proses pembelajaran di kelas, matematika yang terkesan rumit dan menjadi kesan buruk bagi sebagian siswa merupakan kendala untuk siswa dalam menyelesaikan permasalahan-permasalahan sehari-hari yang berhubungan dengan matematika. Kesulitan matematika juga diungkapkan oleh Hasibuan (2018) bahwa kesulitan belajar matematika dapat disebabkan oleh faktor siswa yang tidak mengerti dengan baik dan jelas tujuan dan isi materi dari pelajaran matematika itu sendiri.

Guru memiliki tanggung jawab untuk lebih kreatif dan inovatif dalam menanamkan pemahaman konsep matematika dengan benar. Guru tidak hanya sebatas menyampaikan materi akan tetapi perlu upaya yang kuat untuk membuat siswa benar-benar paham tentang materi matematika disampaikan kepadanya serta dapat mendorong siswa untuk aktif dan partisipatif dalam pembelajaran. Menurut Waskitoningtyas (2016) bahwa ketidakmampuan siswa dalam memahami konsep matematika yaitu kesulitan mengaitkan antara pengetahuan baru dengan pengetahuan sebelumnnya sehingga menimbulkan ketidakpahaman terhadap suatu materi matematika. Penggunaan media dalam pembelajaran dapat dijadikan alternatif solusi oleh guru untuk membantu menguasai prinsip dan konsep matematika secara benar. Menurut Wahyuningtyas \& Ladamay (2016) bahwa penggunaan media dalam pembelajaran matematika selain dapat membantu siswa dalam pembelajaran, juga dapat memberikan pengalaman yang konkrit dan dapat menarik perhatian serta motivasi belajar siswa.

Media pembelajaran merupakan aspek penting dalam pembelajaran karena media dijadikan sebagai alat bantu pembelajaran untuk mengantarkan pesan pembelajaran kepada siswa sehingga belajar siswa semakin bermakna. Menurut Irwaniyati (2018) bahwa pemberian materi tentang konsep atau prinsip matematika yang abstrak dapat dibantu dengan menggunakan media pembelajaran sehingga materi pelajaran matematika menjadi lebih konkrit. Fakta pembelajaran matematika di sekolah menunjukkan masih banyak guru belum maksimal dalam mengembangkan dan menggunakan media dalam pembelajaran matematika. Natasya, Surya, \& Marta (2019) juga mengungkapkan bahwa guru belum maksimal dalam menggunakan media pembelajaran matematika. Hal ini ditunjukan dengan sebesar $85,7 \%$ guru tidak pernah membawa alat peraga untuk menunjang pemahaman siswa dalam memahami materi matematika. Oktari, Handayani, \& Sofyan (2019) juga mengungkapkan dalam hasil penelitiannya pada siswa MI menemukan bahwa guru kurang menggunakan media dalam pembelajaran sehingga siswa mengalami kesulitan menyelesaikan latihan yang diberikan guru. Menurut Astutik (2018) bahwa masih terbatasnya alat peraga maupun media pembelajaran di kelas II Sekolah Dasar, menyebabkan materi perkalian dan pembagian tidak bisa terserap dengan sempurna.

Media medan perkalian dan pembagian bilangan asli didesain untuk dapat digunakan membantu siswa sekolah dasar dalam memahaman konsep perkalian dan pembagian bilangan asli. Siswa perlu memiliki kemampuan pemahaman konsep matematika, agar tidak terjadi miskonsepsi materi matematika itu sendiri. Pada jenjang sekolah dasar, kebanyakan siswa mengenal konsep perkalian dan pembagian dengan cara menghafal. Adanya media 
medan perkalian dan pembagian bilangan asli untuk menjelaskan dan memahamkan konsep materi perkalian dan pembagian sehingga siswa tidak hanya menghafal akan tetapi lebih mudah memahami konsep perkalian dan pembagian untuk membangun pemahaman matematika pada materi matematika selanjutnya.

Artikel ini bertujuan untuk menyajikan cara pembuatan dan penggunaan media medan perkalian dan pembagian bilangan bulat untuk siswa SD sehingga siswa tidak hanya dapat berhitung tentang perkalian dan pembagian bilangan bulat, namun dapat memahami dengan benar konsep perkalian dan pembagian bilangan bulat.

\section{Pemahaman Konsep Matematika}

Pemahaman konsep matematika dalam prinsip pembelajaran matematika tertuang pada (NCTM) bahwa siswa belajar matematika diperlukan pemahaman secara aktif untuk membangun pengalaman belajar yang baru dari pengetahuan sebelumnya (Ningsih, 2016). Pemahaman konsep matematika merupakan dasar untuk mencapai pembelajaran matematika yang bermakna (Yulianty, 2019). Menurut Pirdaus \& Afriansyah (2016) bahwa pemahaman konsep merupakan modal dasar yang perlu dimiliki siswa dalam belajar matematika karena siswa perlu memahami suatu konsep dasar sebelum memahami konsep lainnya.

Pemahaman konsep matematika juga dijelaskan dalam Permendikbud Nomor 58 Tahun 2014 bahwa siswa perlu memiliki kemampuan pemahaman konsep matematika agar mudah menjelaskan hubungan antarkonsep dan menerapkan konsep secara akurat dan tepat dalam memecahkan masalah (Rendrayana, Suarsana, \& Parwati, 2020). Potter \& Kustra dalam (Fatqurhohman, 2016) mengungkapkan untuk tingkat pemahaman siswa yang lebih dalam lagi akan mampu membuat keterkaitan antar beberapa ide matematika dan dapat melakukan generalisasi terhadap suatu konsep sehingga pemahaman konsep matematika siswa tampak pada performa siswa memberikan respon dari ajuan pertanyaan yang diberikan guru.

Pemahaman konsep matematis siswa yang begitu rendah akan berdampak pada proses dan hasil pembelajaran sehingga siswa akan mengalami kesulitan untuk menyelesaikan permasalahan matematika (Triwibowo, Pujiastuti, \& Suparsih, 2018). Matematika tidak berdiri sendiri melainkan memiliki keterkaitan dengan konsep yang lainnya sehingga rancangan pembelajaran matematika dapat menarik perhatian siswa, untuk mau belajar dan mengkonstruksi pengetahuan serta keterampilan berhitung siswa (Purwandari \& Wahyuningtyas, 2017). Ketepatan dalam memilih strategi dan media oleh guru juga menjadi penentu keberhasilan siswa untuk memahami konsep matematika (Indrawati \& Suardiman, 2013).

Berdasarkan uraian diatas, maka pemahaman konsep matematika merupakan kemampuan matematika yang harus dimiliki oleh siswa dalam mengerti dengan mudah konsep-konsep matematika sehingga siswa dapat mengkonstruksi pengalaman belajar matematika yang baru secara bermakna. 


\section{Media Medan Perkalian dan Pembagian Bilangan Bulat}

Media pembelajaran merupakan wadah yang dapat digunakan menyampaikan pesan pembelajaran dari pengirim kepada penerima untuk merangsang pikiran, perhatian dan minat siswa sehingga memberikan efek dalam proses pembelajaran. Menurut Nataliya (2015) baha penggunaan media pembelajaran sangat membantu dalam kegiatan proses pembelajaran sehingga siswa dapat memahami dan mengingat materi yang disampaikan oleh guru secara cepat dan mudah. Menurut Trianto (2010) bahwa media sebagai komponen strategi pembelajaran digunakan untuk menyampikan pesan yang oleh sumber atau penyalurnya ingin diteruskan kepada sasaran atau penerima pesan tersebut. Menurut Astutik (2018) penggunaan media pembelajaran sangat diperlukan pada siswa SD di kelas rendah, karena siswa pada kelompok ini mudah menangkap materi matematika dengan menggunakan media berbasis benda yang nyata/konkrit.

Media memiliki peranan yang sangat penting dalam proses pembelajaran dengan tujuan agar materi yang disampaikan oleh guru mudah diterima oleh siswa secara maksimal (Wicaksono, 2016). Menurut Setyono, Afri, \& Deswita (2016) bahwa pembelajaran dengan menggunakan media dalam proses belajar mengajar memiliki dua peranan penting, yaitu: (1) media sebagai alat bantu mengajar atau disebut sebagai dependent media karena posisi di sini sebagai alat bantu (efektivitas), dan (2) media sebagai sumber belajar yang digunakan sendiri oleh peserta didik secara mandiri atau disebut dengan dependent media. Asyhar (2012) dalam penjelasannya mengungkapkan ada empat jenis media pembelajaran, yaitu: (a) media visual, yaitu jenis media yang digunakan hanya mengandalkan indera penglihatan semata-mata dari peserta didik, misalnya: media visual non proyeksi (benda realita, model protetif, dan grafis), dan media proyeksi (powerpoint, paint dan auto cad); (b) media audio, yaitu jenis media yang digunakan dalam proses pembelajaran dengan hanya mengandalkan indera pendengaran siswa, misalnya: radio, pita kaset suara, dan piringan hitam; (c) media audiovisual, yaitu jenis media yang digunakan dalam kegiatan pembelajaran dengan melibatkan pendengaran dan penglihatan sekaligus dalam satu proses atau kegiatan, misalnya: video kaset dan film bingkai; (d) multimedia, yaitu media yang melibatkan beberapa jenis media dan peralatan secra terintegrasi dalam suatu proses atau kegiatan pembelajaran, misalnya: TV dan power point.

Manfaat media yang diungkapkan oleh Kemp dan Dayton dalam (Karo-Karo \& Rohani, 2018) yaitu sebagai berikut: (1) penyampaian materi pelajaran dapat diseragamkan; (2) proses pembelajaran menjadi lebih jelas dan menarik; (3) proses pembelajaran menjadi lebih interaktif; (4) efisiensi dalam waktu dan tenaga; (5) meningkatkan kualitas hasil belajar siswa; (6) media memungkinkan proses belajar dapat dilakukan di mana saja dan kapan saja.; (7) media dapat menumbuhkan sikap positif siswa terhadap materi dan proses belajar; (8) merubah peran guru ke arah yang lebih positif dan produktif.

Penggunaan media matematika pada pembelajaran jenjang SD memang sangat dibutuhkan untuk membantu anak dalam memahami matematika secara konkrit berdasarkan fakta atau kejadian yang jelas dan dilihat secara langsung (Amir, 2014). Menurut Agung (2017), penggunaan media dalam pembelajaran matematika sebagai jembatan bagi siswa untuk memahami konsep abstrak dari obyek matematika melalui manipulasi benda-benda nyata. 
Media medan perkalian dan pembagian bilangan asli merupakan media pembelajaran yang dapat digunakan untuk menunjukkan atau membantu siswa SD dalam memahami konsep perkalian dan pembagian. Hal ini sejalan sejalan dengan pendapat (Wahyuningtyas \& Ladamay, 2016) bahwa penggunaan media pembelajaran untuk siswa SD untuk memberikan pengalaman belajar matematika secara konkrit dan menarik perhatian, motivasi belajar dalam diri siswa. Menurut (Amir, 2014) melakukan manipulasi alat peraga untuk memahami konsep matematika sejalan dengan karakteristik siswa SD yang memiliki rasa ingin tahu yang kuat dan tertarik untuk mengekplorasi situasi di sekitar lingkungannya. Dalam penggunaan media medan perkalian dan pembagian bilangan asli akan membuat siswa menjadi lebih berpartisipasi dalam proses pembelajaran matematika materi perkalian dan pembagian karena media ini dapat dijadikan alat bermain dan belajar di mana siswa dapat menempelkan magnet sekaligus dapat berhitung sehingga siswa akan menikmati proses pembelajaran yang sedang berlangsung dan lebih memahami materi yang sedang diajarkan.

Langkah-langkah membuat media medan perkalian dan pembagian bilangan bulat adalah sebagai berikut.

1. Potong papan kayu dengan ukuran masing-masing dengan panjang $50 \mathrm{~cm}$ dua bilah, 60 cm dua bilah.

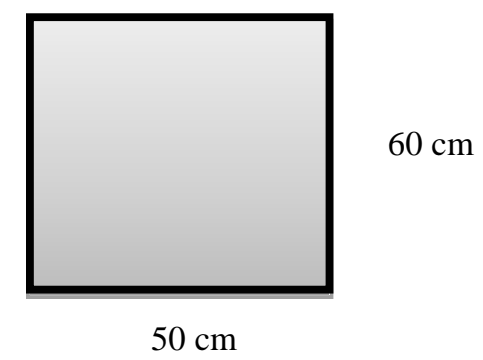

Gambar 1. Ukuran Papan Kayu Untuk Pembuatan Media

2. Satukan 4 bilah papan tersebut menjadi kerangka berbentuk persegipanjang dengan bilah ukuran $50 \mathrm{~cm}$ sebagai panjang dan bilah ukuran $60 \mathrm{~cm}$ sebagai lebar.

3. Tutup seluruh bagian depan kerangka tersebut dengan plat seng dengan cara dipaku bagian pinggirnya

4. Tutupi setiap sisi papan tersebut dengan menggunakan bingkai dari kayu dengan ukuran masing-masing dengan panjang $50 \mathrm{~cm}$ dua bilah, $60 \mathrm{~cm}$ dua bilah dengan lebar yang sama yaitu $3 \mathrm{~cm}$.

5. Untuk mempercantik media guna meningkatkan minat peserta didik, maka media tersebut diwarnai dengan piloks dan cat atau ditambahkan aksesoris selengkapnya.

6. Buatkan kotak perkalian dan pembagian dengan ukuran 3,5 cm sebanyak 100 kotak. Untuk bilangannya buatkan kotak sebanyak 10 pada bagian atas dan 11 kotak pada bagian samping kanannya. 


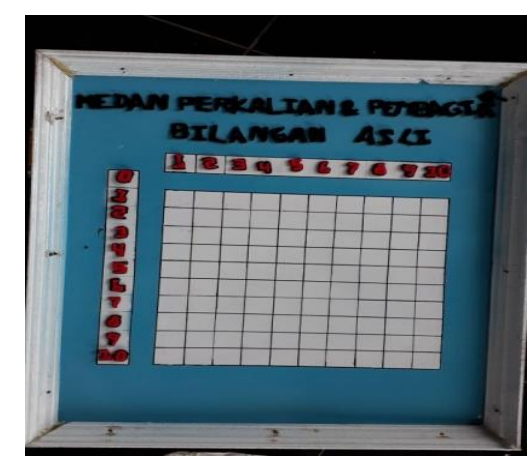

Gambar 2. Pembuatan Kotak Perkalian dan Pembagian

7. Untuk tempelannya terbuat dari magnet. Buatkan lingkaran berdiameter $3 \mathrm{~cm}$ sebanyak 100 buah dari map plastik, kemudian tempelkan pada setiap magnet. Setelah selesai media tersebut terlihat seperti gambar di samping.

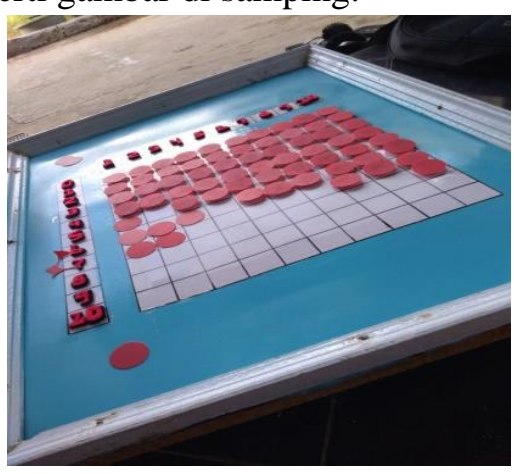

Gambar 3. Pemberian Tempelen dari Magnet

Media pembelajaran ini digunakan untuk mengajarkan konsep perkalian dan pembagian bilangan asli pada kelas II SD di mana bilangannya terbatas karena hanya disediakan 100 buah magnet. Berikut diuraikan cara penggunaan media medan perkalian dan pembagian bilangan bulat yaitu sebagai berikut.

a) Untuk Perkalian

Misalnya : $3 \times 4=\ldots$

1) Ambil magnet sebanyak bilangan yang dikali, dari contoh ambil magnet sebanyak 4 buah.

2) Tempelkan magnet tersebut pada setiap baris, jadi setiap baris di isi sebanyak 4 buah magnet.

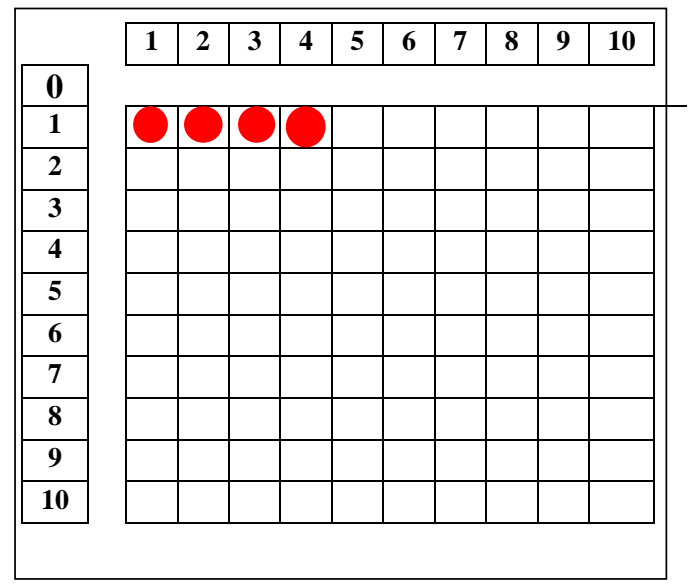


3) Lakukan hal yang sama seperti langkah no 1 dan 2 sebanyak bilangan pengali, dari contoh sebanyak 3 kali .

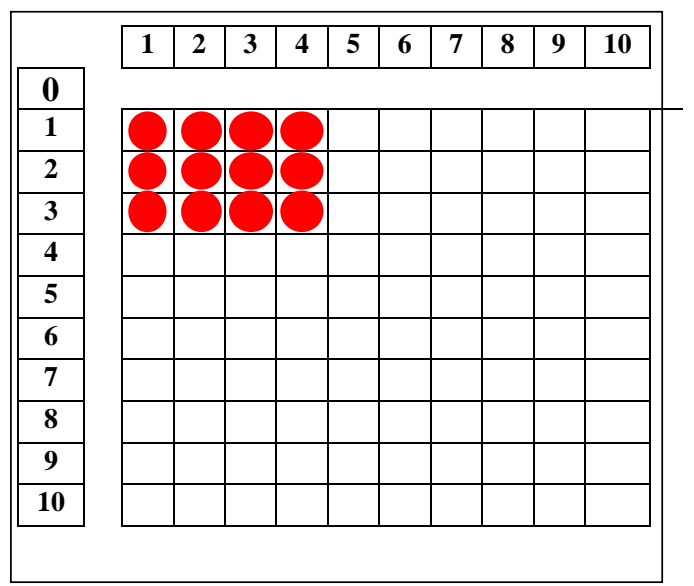

4) Jumlahkan setiap magnet yang terisi pada setiap baris, karena ada 4 magnet yang terisi pada 3 baris maka jumlahnya adalah $4+4+4=12$. Jadi hasil perkaliannya adalah 12 .

b) Untuk pembagian

Misalnya : $12 \div 4=\ldots$

1) Ambil magnet sebanyak bilangan yang dibagi, dari contoh ambil magnet sebanyak 12 buah.

2) Tempelkan magnet tersebut pada setiap kolom sebanyak bilangan pembagi, jadi setiap kolom diisi sebanyak 4 buah magnet.

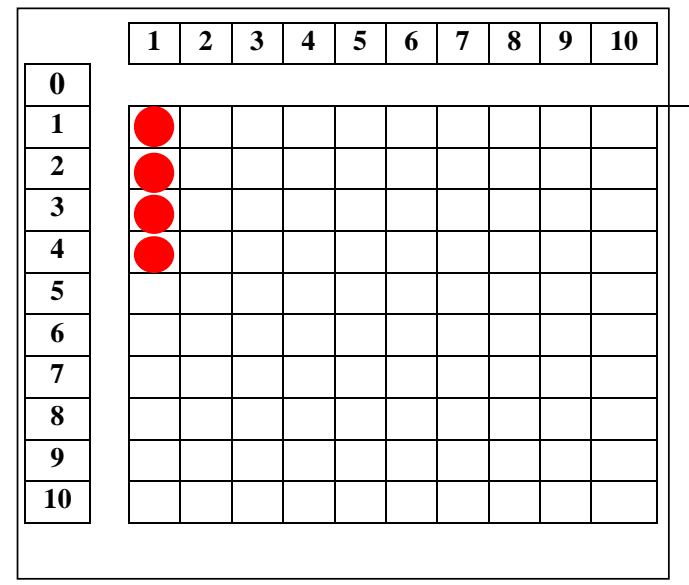

3) Lakukan hal yang sama seperti langkah no 2 sampai magnet yang diambil habis.

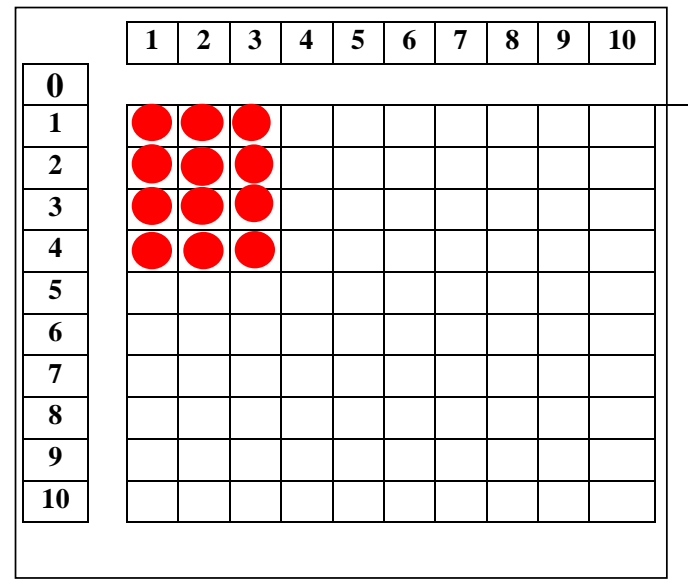


4) Untuk mendapatkan hasil baginya, lihat pada kolom ke berapa magnet tersebut habis $12-4=8-4=4-4=0$. Magnet tersebut habis pada kolom ke 3. Jadi, hasil baginya adalah 3 .

\section{Kesimpulan dan Saran}

Media medan perkalian dan pembagian bilangan bulat didesain secara sederhana sehingga dapat dibuat dengan mudah, tidak memerlukan biaya yang cukup mahal, dan mudah digunakan oleh guru SD dalam mengenalkan konsep perkalian dan pembagian bilangan bulat serta dapat menarik perhatian siswa dalam belajar matematika konsep perkalian dan pembagian. Dengan media ini, siswa SD kelas II tidak hanya dapat berhitung tentang perkalian dan pembagian bilangan bulat, namun dapat memahami dengan mudah konsep perkalian dan pembagian bilangan bulat.

\section{Daftar Pustaka}

Agung, S. (2017). Pemanfaatan Aplikasi Geogebra Dalam Pembelajaran Matematika SMP. Prosiding Seminar Nasional Universitas Cokroaminoto, 3(1), 312-322.

Amir, A. (2014). Pembelajaran Matematika SD dengan Menggunakan Media Manipulatif. Forum Paedagogik, 6(1), 72-89.

Asfiah, I., \& Sulistyowati, E. (2010). Mengajarkan Perkalian di Kelas II SD/MI dengan Strategi Permainan. AI-Bidayah, 2(2), 231-254.

Astutik, I. S. (2018). Pengembangan Media Pembelajaran "Kalingga" Untuk Meningkatkan Hasil Belajar Matematika Pada Materi Perkalian Dan Pembagian. Indonesian Digital Journal of Mathematics and Education, 5(9), 623-628.

Asyhar, R. (2012). Kreatif Mengembangkan Media Pembelajaran. Jakarta: Referensi Jakarta.

Fatqurhohman. (2016). Pemahaman Konsep Matematika Siswa Dalam Menyelesaikan Masalah Bangun Datar. Jurnal Ilmiah Pendidikan Matematika, 4(2), 127-133. http://doi.org/10.25273/jipm.v4i2.847

Hasibuan, E. K. (2018). Analisis Kesulitan Belajar Matematika Siswa Pada Pokok Bahasan Bangun Ruang Sisi Datar di SMP Negeri 12 Bandung. AXIOM : Jurnal Pendidikan dan Matematika, 7(1), 18-30. http://dx.doi.org/10.30821/axiom.v7i1.1766

Herlina, E. (2016). Efektitas Media Jendela Kejutan Untuk Meningkatkan Kemampuan Mengenal Lambang Bilangan Bagi Anak Tunagrahita Ringan. Jurnal Ilmiah Pendidikan Khusus, 5(1),62-77.

Indrawati, D., \& Suardiman, S. P. (2013). Pengembangan Media Travel Game Untuk Pembelajaran Perkalian Dan Pembagian Bilangan Pecahan Matematika SD Kelas V. Jurnal Prima Edukasia, 1(2), 135-146. https://doi.org/10.21831/jpe.v1i2.2631

Irwaniyati, I. (2018). Pemanfaatan Media Pembelajaran konsep perkalian dan pembagian di MI. Indonesian Journal of Islamic Teaching, 1(1), 88 -109.

Karo-Karo, I. R., \& Rohani. (2018). Manfaat Media Dalam Pembelajaran. AXIOM : Jurnal Pendidikan dan Matematika, 7(1), 91-96. http://dx.doi.org/10.3082/axiom.v7i1.1778

Nataliya, P. (2015). Efektivitas Penggunaan Media Pembelajaran Permainan Tradisional Congklak Untuk Meningkatkan Kemampuan Berhitung Pada Siswa Sekolah Dasar. Jurnal Ilmiah Psikologi Terapan, 3(2), 343-358. https://doi.org/10.22219/jipt.v3i2.3536

Natasya, N. D., Surya, Y. F., \& Marta, R. (2019). Analisis Faktor Penyebab Kesulitan Belajar Matematika di Kelas IV Sekolah Dasar Negeri 004 Bangkinang Kota (Materi Pecahan). Jurnal Riset Pembelajaran Matematika Sekolah, 3(2), 47-54.

Ningsih, Y. L. (2016). Kemampuan Pemahaman Konsep Matematika Mahasiswa melalui Penerapan Lembar Aktivitas Mahasiswa (LAM) Berbasis Teori Apos Pada Materi Turunan. Edumatica, 6(1), 1-8. https://doi.org/10.22437/edumatica.v6i01.2994 
Oktari, E. Z., Handayani, T, \& Sofyan, F. A. (2019). Analisis Kesulitan Belajar Matematika Materi Operasi Hitung Campuran Siswa MI Hijriyah II Palembang. Al-Adzka: Jurnal Ilmiah Pendidikan Guru Madrasah Ibtidaiyah, 9(1), 41-50.

Pirdaus, D. A., \& Afriansyah, E. A. (2016). Pembelajaran Kooperatif Tipe Team Assisted Individually untuk Meningkatkan Kemampuan Pemahaman Matematis Siswa Sekolah Menengah Pertama. Jurnal Pendidikan Matematika RAFA, 2(1), 104-122.

Purwandari, A., \& Wahyuningtyas, D. T. (2017). Eksperimen Model Pembelajaran Teams Games Tournament (TGT) Berbantuan Media Keranjang Biji-Bijian Terhadap Hasil Belajar Materi Perkalian Dan Pembagian Siswa Kelas II SDN Saptorenggo 02. Jurnal Ilmiah Sekolah Dasar, 1 (3), 163-170. http://dx.doi.org/10.23887/jisd.v1i3.11717

Rendrayana, K., Suarsana, I. M., \& Parwati, N. N. (2020). Strategi Pembelajaran Analogi dan Kemampuan Pemahaman Konsep Matematika. Jurnal Pendidikan Matematika RAFA, 6(1): 1527. https://doi.org/10.19109/jpmrafa.v6i1.5515

Setyono, T., Afri, L. E., \& Deswita, H. (2016). Pengembangan Media Pembelajaran Matematika Dengan Menggunakan Macromedia Flash Pada Materi Bangun Ruang Kelas VIII Sekolah Menengah Pertama. Jurnal Ilmiah Mahasiswa FKIP Prodi Matematika, 2(1), 1-10.

Trianto. (2010). Mengembangkan Model Pembelajaran Tematik. Jakarta: Prestasi Pustaka.

Triwibowo, T., Pujiastuti, E., \& Suparsih, H. (2018). Meningkatkan Kemampuan Pemahaman Konsep Matematis Dan Daya Juang Siswa Melalui Strategi Trajectory Learning. PRISMA, Prosiding Seminar Nasional Matematika, 1, 347-353.

Wahyuningtyas, D. T., \& Ladamay, I. (2016). Meningkatkan Pemahaman Konsep Perkalian Dan Pembagian Bilangan Bulat Menggunakan Media Wayangmatika. Pancaran, 5(3), 51-60.

Waskitoningtyas, R. S. (2016). Analisis Kesulitan Belajar Matematika Siswa Kelas V Sekolah Dasar Kota Balikpapan Pada Materi Satuan Waktu Tahun Ajaran 2015/2016. Jurnal Ilmiah Pendidikan Matematika, 5(1), 24-32. http://doi.org/10.25273/jipm.v5i1.852

Wicaksono, S. (2016). The Development Of Interactive Multimedia Based Learning Using Macromedia Flash 8 In Accounring Course. Journal of Accounting and Business Education, 1 (1), 122-139.

Yulianty, N. (2019). Kemampuan Pemahaman Konsep Matematika Siswa Dengan Pendekatan Pembelajaran Matematika Realistik. Jurnal Pendidikan Matematika Raflesia, 4(1), 60-65. https://doi.org/10.33449/jpmr.v4i1.7530 